\title{
Feedback
}

\section{HSM and women?}

One would of course expect that humanistic view of management should appeal to women, that we should see them leaving those 'boring' courses in finance, accounting, and computer science, and joining HSM in beehives. Well, far from it.

Human Systems Management, for whatever reasons, has not attracted women into its ranks. Frankly, there are no women in HSM. You can find them in real estate, in advertising, in sales, on Wall Street, everywhere in business - except in humanoriented fields of management.

There were some women in HSM in the early days - they are all gone now. Let me try to recall some of them. First, Anita Lands, who was at the very beginning of HSM, left for Catalyst, Inc. and never came back. Many other women followed similar path: Margie Craig (joined and disappeared), Barbara Marx Hubbard (tried few things about the future SYNCON, disappeared), Irene A. Jillson (activist, full of ideas, gone), Valarie $C$. Lamont (wrote us few

\section{Out of human scale?}

Professor Lowen's "Creep-Creep" is creeping upon us in one area which he neglects to mention: publishing of academic papers.

There were times when papers written by scientists were submitted in a handwritten form: hence, manuscript - written by hand. Handwriting invited corrections, scratching over, refining - a typesetter's nightmare. Writing and style were generally good, human side of the writer not hidden.

Then typewriters took over. First demanded by typesetters' unions and later reluctantly adopted by

North-Holland Publishing Company

Human Systems Management 2 (1981) 221-226 letters, silent now), Anna Ostanello-Boreani (joined and never responded to any thing), Marion S. Vittitow (joined and left), Christel M. Capdevielle (assumed editorship of HSM Co-Enzyme, resigned de facto, without notification), and so on. We asked Marylin Ferguson to join (declined), Anne S. Huff to serve on HSM editorial board (declined) and Emma Rothschild to write for us (declined). In the meantime, Mary $L$. Baetz and Jo-Ann C. Dixon have joined HSM but remained extremely passive.

A very small number of women expressed interest in promoting the marriage of rational-logical and intuitive aspects of management through Human Systems Management. Those who contemplated such possibilities have quickly abandoned the bleaker and harder realities. Thus, HSM has no women seriously involved in its endeavors. Where did the editors and organizers of HSM go wrong?

Milan ZELENY

writers themselves, typewritten manuscripts became one of the necessary conditions for acceptance. Orderly, print-like layout of words makes it less inviting for authors to introduce corrections, to refine, to tune up their writing. New type of error appears, a typo; the quality of writing is slowly but surely deteriorating. Many writers, especially professionals, type their work themselves; there is still some support for calling the product a manuscript.

But the typist, the actual producer of the manuscript, starts to dominate the field. Overwhelming majority of scientists are having their manuscripts typed by somebody else. Partially because they cannot type themselves. Many abandon the ritual of writing altogether and dictate their precious sentences into a 
dictaphone, a tape of their voice is submitted to the typist. The quality of writing further deteriorates. One cannot turn a good sentence by simply dictating (except well oiled clichés), one has to work on it, one has to struggle, one has to care. Good writing and skillful use of language is discouraged and the 'fools' who care are labeled 'wordsmiths'. A specialist needs about 1000 words to turn out an acceptable scientific paper.

Such simplicity of language is self-enhancing. Many scientists who originally would not write well now simply cannot write at all. Dictating is taking over and a feverish research into voice-reading and voiceprinting is going on. Such advances become indispensable for the severely handicapped.

A new 'creep-creep' manuscript has made its appearance in the recent years: a computer-generated manuscript. These high-speed printed productions are so precise, so incredibly monotonous, so mechanically perfect, that any intervention, even a small scratch-line, is destroying the intended high-technology impact. So, the writters do not interfere, they do not proofread, they submit 'manuscripts' untouched by human hand. The quality of writing is atrocious, errors are not only frequent but also ingenious and novel. Computer is to be blamed, not the author. Somehow, computer is forgiven.
Computer-generated manuscript is the ultimate creep-creep, even among those who write about creep-creep. The art of writing is gone. The author talks something into something else, the secretary punches it into computer memory and makes a print. A beautiful print. It looks so perfect that it would be a $\sin$ to read it and correct it. To the editor it goes. Let the editor worry that 'pentient' actually means 'penchant'.

As a strong supporter of intelligent electronics and high technology in general, I find it ironic responding to computer-generated manuscripts in this way. But then I realize that a tool, any tool, is only as good as the craftsman using it. A knife in hands of a small child or deranged psychic could be deadly. Any tool could get out of hand, out of human scale. Or, the human scale itself is shifting on us - maybe that all these atrocities are human, represent a new human scale, new human measure of values.

Of course that computers, word-processors and artificial or machine intelligence are here to stay. But should they replace rather than enhance human intelligence? Cannot we use them with skill? Cannot we, with their help, resurrect and cultivate the art of human writing and thus human communication?

Milan ZELENY

\section{Can we do book reviews better?}

Some HSM readers and editors (including this one in the lead) have not been extremely enthusiastic about the quality of some HSM book reviews, reviewers' skills, and the variety of books selected. We are indeed fortunate that Professor John P. van Gigch of the California State University in Sacramento has agreed to edit the section of "Reviews". I am sure that it will receive a sense of purpose and focus; better and more exciting writing, and more varied and up-to-date selection. From Vol. 2, No. 4, HSM reviews will appear under 'new management'. Let us hope that all readers and editors will help and submit their comments, suggestions, and review proposals to Professor van Gigch. We do consider book reviews to be an important part and duty of any self-respecting publication. HSM is committed to ful- fill this duty at the highest level of quality, informativeness and responsibility.

Perhaps, one day, HSM reviews could become comparable to those which we encounter in The New York Review of Books, a truly remarkable publication of quality, now in its 28 th volume. Or to those published in Science, a leading scientific journal of 100 years of tradition and experience.

Are these unattainable ideals? I think that HSM has more than a good chance to achieve similar levels of readers' attention and satisfaction. I have just opened an issue of Science (22 May 1981, 913-914) and found a review which obviously was judged as being suitable for publication. I cannot resist quoting excerpts from this review - not reflecting on the quality of the book reviewed - but pondering the 
nature of editorial decision making and judgment. I quote only the first and the last paragraphs of the review:

At the invitation of the Honourable Miriam Rotschild, 58 delegates representing 15 nationalities assembled to convene the First International Conference on Fleas. The conference was formally opened with an address by Sir Vincent Wigglesworth, and during morning sessions of the following four days 33 papers or their abstracts were delivered. It is these that make up this volume.

Then follows the listing of papers and abstracts presented, including such items as annotated biography of Nathaniel Charles Rothschild and a bibliography of his publications (Rotschild came from the well-known British banking family), a review of studies on fleas in the U.S.S.R., zoogeography and evolution in fleas, lice, and mammals, and so on. The reviewer concludes:

A few of the papers included in this volume constitute major contributions to our knowledge of the order Siphonaptera, and most of the remainder are appropriate for inclusion, albeit somewhat parochial. Both the binding and the type are pleasing to the eye, and for a publication of this type the book is remarkably free of mechanical flaws. However, though this is a book that will appeal to students of the order Siphonaptera, it is not likely to attract a broad audience in the more applied fields of medical and veterinary entomology.

The above excerpted review reached some 180000 readers of Science. Can we do book reviews better?

Milan ZELENY

\section{Economics, ethics, and cost-benefit analysis: a comment}

It is a legitimate exercise of economic analysis to examine the consequences of various value judgments, whether or not they are shared by the theorist, just as the study of comparative ethics is itself a science like any other branch of anthropology.

Samuelson [4]

Professor Daly's eloquent discourse on the paucity of adequate solutions to present world problems highlights the need for new perspectives and a change in the ranking of values in a world wrought with overpopulation and overconsumption. Professor Daly has become the standard reference on pointing out courageously how misguided institutions can be in pursuing economic growth at all costs. As such, he is considered the conscience of Economics.

In his article in a recent issue of this Journal (HSM 2 (1) (1981) 7-12), Professor Daly accurately observes that economists do not bring to their methodology preconceived ethical premises. Indeed this perspective was particularly stressed by Lionel Robbins [3] who convinced many economists that ethical value judgments have no place in scientific analysis. However, one would be hard pressed today to find a significant number of economists who would not refer to Economics, as physicians refer to medicine, as a technique, not a science. Therefore, his suggestions that both the discipline overlooks the causes and consequences of ecological and existential scarcity, and that economists fail to understand the ethical character of economic decisions would prompt even an idealist to take up the sword in defense of his (her) scholastic roots.

Professor Daly's concern over what he calls the "emerging world crisis" is shared by most reasonable people; however, one is particularly attuned to his use of generalities. A global consensus on a "proper ranking of social values" necessitates fundamentally that the world's community of citizens be able to communicate clearly with each other. Precise communication demands the abandonment of politically emotive catch terms that on the one hand, confuse people interested in the rudimentary features of controversial issues, and on the other hand, divide otherwise compatible collegues.

Historically, the determination of sound values, right purposes, and standards for moral growth has been in the domain of priests, autocrats, or the voting 
public. Indeed, social science evolved into a distinct discipline precisely because the responsibility to prescribe values and social goals was lodged in other quarters. To charge the social sciences with the duty of determining the proper rank ordering of global values is, conversely, to expect econometric forecasts from priests. We cannot deny witnessing efficiency from the division of labor; otherwise, public institutions, in their decisions about financial support, would have been unable to distinguish technology from alchemy. True, efficiency can only be defined in the context of a predetermined set of social priorities. But in democratic societies, is it not the majority that selects those goals?

Daly provides a necessary component of social values as ". . . that which does not promote the indiscriminate destruction of terrestrial life." But what does 'indiscriminate' mean? Is there a safety trade-off between terrestrial and extraterrestrial life? How can we predict the outcomes of alternative safety measures in the absence of standard methodology? To "... declare knowledge attained by introspection invalid" is, indeed, a manifestation of prejudice. But who would not argue that application of a policy based on introspection carries enormous costs, the recognition of which is facilitated through adoption of rigorous methods.

The observation that the social merely mimic the physical sciences indicts a necessary state toward the future synthesis of disciplines operating in disjunction. How much more responsible can value judgment be as compared to mechanical calculation. Surely, the latter was not what caused the Spanish Inquisition, or the former, the Copernican Revolution. Appeal to the poverty of cost-benefit analysis in decisions about appropriate technologies ignores its potentially qualitative application. Decisions about the use of fossil versus solar fuels are based only partly on the results of cost-benefit studies. Either self-indulgent policy makers do not like those results, or the quality of those results has been compromised by the degree of dispassion brought to the methodology by researchers. Thus, the decision to employ science or moral judgment hinges on the comparison of the relative degrees of error brought to the evaluative process by both the methodology and the researcher.

If mechanical calculation reduces individual responsibility in the evaluation of quality, it gains in the imposition of equitable treatment over those subject to the review process. If a retreat to qualitative evaluations regained fashion, what criteria would select the autarchy? Who would determine the criteria? No one can disagree with the error in a "compulsion to substitute (completely?) mechanical calculation for responsible value judgment." But the thrust of Daly's paper fails to highlight the synergistic potential for exponentially improved decisions (improved in that society more closely approaches, dare I say, a Pareto optimum) that result from the application of moral constraints to optimization techniques.

Moral constraints are nothing new to the costbenefit process. For a more complete illustration, an explanation from Mishan is helpful. The economist provides answers to the questions

(a) is there an aggregate net gain in undertaking a policy, and

(b) if the policy exists, would the removal of the policy result in a net gain?

When the answers to these are positive and negative, respectively, the community clearly will experience a net gain and the economist, in turn, suggests adoption of the policy. We must distinguish between a Pareto improvement and a distributive improvement. The former is defined as an economic change that improves the lot of one or more people without making anyone worse-off. It omits evaluation of the distributional characteristics of the rearrangement. The latter suggests a major concensus that the change in the distribution is an improvement.

The adoption of either proposition depends on whether the economist's welfare methodology is developed from a utility or an ethical perspective. Within the former, every effect on an individual's utility is important. Within the latter, the economic calculus permits only those effects allowed by a 'social constitution' determined by broad consensus. Mishan is not alone in observing

... a majority in power is capable of irresponsible and even tyrannical behavior towards individuals and minorities. There can be no reasonable expectation, in particular where legislation is influenced by party doctrine, that majority decisions will always respect minority interests, or even views that are widely held in society. [2]

The ethical approach evaluates only a select number of spillover effects. Excluded are elements in the subset of what is called interdependent utilities; that is, effects from the mere knowledge of events, otherwise external to the individual. These include envy, ethnocentrism, hatred, love, compassion, a 
feeling of community, concern for future generations, etc. Therefore, resort to the ethical approach excludes precisely what Professor Daly wishes to incorporate into the economic calculus. Incorporation of interdependent utilities appeals to the traditional Pareto view, and Economics is acquitted.

One infers that Professor Daly has chosen a hybrid approach which permits only select elements in the subset of interdependent utilities that carry humane qualities. Then, the quintessential inquiry concerns the choice of political systems which will ferret out those elements. The area in Economics called Public Choice Theory assumes selection is made by majority rule under various states of power. If majority rule includes elements such as envy, hate, ethnocentrism, egotism, sadism, impermissible into the method, then the only alternative is a resort to tyranny (The Impossibility Theorem), the major result of which is an abrogation of individual responsibility.

Daly provides an excellent summation of this Comment when he states that "The real issue is not economic, but ethical." Here he implies that it is not economists, but rather those responsible for ethics, who have neglected their duty. To clarify this point, one must distinguish between two categories - economists, and economic performers. The former combine objectivity with traditional economic methodology in the evaluation of a policy, or a project, under alternative states of nature, which in effect, may refer to various ethical perspectives. The evaluations are then available to policy makers. Those in the other category, not unlike attorneys, are hired for the specific purpose of representing, and publicizing apologies for employers. Employers, ranging from the Chamber of Commerce to the Hoover Institution, largely comprise either private business interest groups, or research institutions. with private affiliations. One observes the relative plethora of economic performers. Why? The efficiency of the market. The information content of prices. The law of supply. This is not to say that graduate students of Economics are not subjected to significant pressure to conform to the political, as well as academic, standards of their future colleagues. Rather it is to suggest that the error lies, not in the craft, but in the artisan.

\section{Marie LOBUE \\ Department of Economics and Finance University of New Orleans New Orleans, LA 70122, U.S.A.}

\section{References}

[1] H.E. Daly, Economics, ethics, and cost-benefit analysis, Human Systems Management 2 (1981) 7-12.

[2] E.J. Mishan, Cost-Benefit Analysis (Praeger, New York, 1976).

[3] L. Robbins, An Essay on the Nature and Significance of Economic Science (London, 1932).

[4] P. Samuelson, Foundations of Economic Analysis (Harvard University Press, Boston, 1974).

\section{Economics, ethics, and cost-benefit analysis: a reply}

Our subject in popular versions of it, sometimes even in the hands of distinguished writers, has furnished forth for the ungodly blunt instruments with which to bludgeon at birth useful projects of social betterment.

A.C. Pigou

Dr. Lobue's comment raises some important questions and I am glad to respond briefly to some of them. I certainly agree that we should not expect econometric forecasts from priests. My main point is that we are more in danger of committing the oppo- site error of seeking divine guidance from econometric forecasts, or from cost-benefit calculations. Indeed, as suggested in the above quote from Pigou, costbenefit is a blunt instrument easily weilded by the ungodly! Granted that the error is mainly in the artisan rather than the craft, it seems to me that part of the artisan's error is an exaggerated faith in the tools of his craft.

Certainly the clear separation of is from ought is an elementary rule of clear thinking. But I suggest that the distinction belongs in the mind of the individ- 
ual thinker and should not be a criterion for professional specialization. The current division of labor between is-professions and ought-professions leads to a total lack of connection between the two. Each goes its own way unconstrained by the other, with the is-professions in the ascendency and the oughtprofessions treated as a vestigial superstition left over from the Middle Ages. This is dangerous.

Incorporation of interdependent utility functions would be one way of explicitly integrating ethics into economic theory, as Dr. Lobue suggests. However this is almost never attempted. Economists assume independent utility functions, but independence (indifference) is as much an ethical relationship as are various forms of interdependence (altruism, envy). When economists apply the Pareto criterion they are asserting either:

(a) that individuals are in fact not spiteful or envious, or

(b) that individuals ought not be spiteful or envious,

and if they happen to be so these feelings deserve no weight in social decisions. Assertion (a) is factually false and assertion (b) is a value judgment. If some envious people feel worse off whenever anyone else is better off then the Pareto criterion is not operational. Economists have implicitly made the ethical judg- ment that wants based on envy and spite should receive zero weight in social cost-benefit decisions, even though these wants clearly influence the market prices which we are otherwise trying to approximate in cost-benefit analysis. I see no great difficulty in going on to argue that the wants based on 'envy, hate, ethnocentrism, and sadism' should be given zero weight in social decisions, and that this does not imply a tyranny if there is a genuine consensus that such 'values' are unworthy or negative. Without such a consensus there is no alternative to either tyranny or anarchy, and no real sense in speaking of abrogation of individual responsibility because there would be no moral context within which to define responsibility. As Burke said, the less restraint comes from within (shared values), the more must come from without (police powers). That is why it is so important to insist on the necessity of at least a minimal consensus on values, and why the undermining of that consensus by the postivistic tendency to treat values on a par with personal preferences is so dangerous.

Herman E. DALY

Department of Economics Louisiana State University Baton Rouge, LA 70803, U.S.A. 